\title{
DETERMINATION AND EVALUATION OF RAILWAY AGGREGATE SUB-BALLAST GRADATION AND OTHER PROPERTIES VARIATION
}

\author{
Deividas NAVIKAS ${ }^{\mathrm{a}}$, Matas BULEVIČIUS ${ }^{\mathrm{b}}$, Henrikas SIVILEVIČIUS ${ }^{\mathrm{a}}$ \\ ${ }^{a}$ Department of Transport Technological Equipment, Vilnius Gediminas Technical University, \\ Plytinès g. 27, LT-10105 Vilnius, Lithuania \\ bJSC "Granitine skalda", Granito g. 2, LT-02241 Vilnius, Lithuania
}

Received 26 Oct 2015; accepted 04 Apr 2016

\begin{abstract}
The use of high quality aggregate mixture, proper technological parameters of laying and compacting as well as the required thickness of the mixture ensures railway sub-ballast layer properties. In this paper gradation, density and water permeability of 49 produced random samples of aggregate sub-ballast (ASB) mixture which were taken from the stockpile in the plant and from the uncompacted railway layer are investigated. The statistical parameters of the ASB mixture quality indicators and histograms with theoretical curves of normal distribution are presented as well. Their conformity to normal distribution was tested through the use of skewness, kurtosis, Pearson, Shapiro-Wilk and Kolmogorov-Smirnov methods. Regression analysis was employed to determine the dependence of standard deviation of percent passing on the mean percent passing through the sieves. In this paper a new method of determining the homogeneity of ASB according to the variation of gradation using the maximum standard deviation value of this dependence was employed. The minimum size $n$ was calculated with the permissible relative error of $5 \%, 10 \%, 15 \%$ and $20 \%$. The obtained research findings revealed that due to segregation processes the homogeneity of ASB mixture from the point of its production to application has decreased by about $38 \%$.
\end{abstract}

Keywords: railway track, aggregate sub-ballast (ASB), gradation, water permeability, mixture density, stockpile, layer, homogeneity, normal distribution, sample size.

\section{Introduction}

Each transport mode involves interaction of vehicles, transport infrastructure, freight and traffic participants. Beside positive results of this interaction there are also negative effects: traffic accidents and environmental pollution (Podvezko, Sivilevičius 2013). In railway transport the quality of passenger transportation depends on the criteria describing the train elements and the technical state of the railway track (Maskeliūnaite, Sivilevičius 2014; Sivilevičius, Maskeliūnaite 2014). The railway track ballast, sub-ballast and railway bed under the effect of traffic loads, climate and ambient air factors undergo deformations causing changes in the track quality index (TQI) (Bai et al. 2015; Arasteh Khouy et al. 2014a; Xu et al. 2011).

Bing and Gross (1983) presented a model that could be used to predict how the track quality, measured in terms of track quality indices, changes as a function of causal parameters, such as traffic, track type and maintenance.

Substructure instability can be caused by weak subgrade soils, ballast breakdown, poor-quality ballast, thick- ness of the ballast and top formation layers. Sources of ballast fouling consist of ballast particle degradation, infiltration of fine foreign particles from the track surface, sleeper wear as well as sub-ballast and subgrade infiltration (Selig, Waters 1994).

According to Shahu et al. (1999), Soliman and Shalaby (2014) there are two factors affecting the railway track life cycle. Subgrade modulus was found to have the greatest influence on overall track responses. The next most important factors affecting the overall track response were sub-ballast depth, rail moment of inertia, and tie spacing. The subgrade stresses decreased as the subballast depth increased, reducing the tie deflection and sub-ballast strain significantly and indicating an overall track improvement, which was also reflected in the improvement of the track modulus.

The dynamic behaviour of ballasted track with and without tyre-derived aggregate (TDA) as sub-ballast layer was assessed using the impulse-response (IR) test. The obtained results were represented in three different kinds of velocity-time, velocity-distance and velocity-frequency curves. It was proved that TDA with the particle size

Corresponding author: Deividas Navikas

E-mail: deividas.navikas@vgtu.lt 
of 5-50 $\mathrm{mm}$ and the thickness of $200 \mathrm{~mm}$ reduced by 6-47 dB in vertical vibrations with the dominant frequency range of 32-63 Hz (Esmaeili, Razaei 2016).

In flexible pavement structures, stiffness of unbound granular layers and subgrade soil significantly contribute to the overall performance of the pavement system. The stiffness of pavement unbound materials is widely characterised by the resilient modulus which is obtained from repeated load triaxial (RLT) tests. Although pavement unbound materials are usual in partially saturated conditions and experience seasonal moisture content and, therefore, suction variations in the field, their stiffness is conventionally characterised using the total stress approach (Salour, Erlingsson 2015).

The research was conducted with railroad ballast, biaxial geogrid, nonwoven geotextile, and geocomposite inclusions placed at the ballast-subballast and subballastsubgrade interfaces. The investigation revealed that geogrid and geocomposite dual-layer reinforcement at the ballast-subballast interface outperforms single-layer reinforcement when reducing settlement (Indraratna, Nimbalkar 2013; Mishra et al. 2014).

Geosynthetics was used on railway test sections where different forms of sub-ballast reinforcement were employed, which reduced the compressibility of the system. Reduced breakage of the ballast material and greater abrasion resistance were observed in the test sections with geosynthetics and the use of a thicker, more durable geotextile would have been more appropriate (Fernandes et al. 2008).

Another alternative technical solution is to use hot mix asphalt (HMA) layer between the ballast and subgrade, which acts not only as a flexible layer reducing stress on the track subgrade, but also operates as a sealant which blocks water penetration into the subgrade and the bedrock (European Asphalt Pavement Association 2003).

Bituminous mixtures could be used as an alternative material for sub-ballast layers. Thus, some recommendations to model this material are included. Bituminous mixtures consist of a combination of aggregates and hydrocarbon-based binders, where the latter form continuously fills these envelopes with the aggregates. Individually, the behaviour of the aggregates is elastoplastic and that of the binders is viscoelastic. However, when combined, the resulting bituminous mixtures are considered viscoelastoplastic materials. This solution might bring relevant advantages in terms of subgrade protection and life cycle: to track differential settlement and dynamic performance (Gallego et al. 2013; Teixeira et al. 2009, 2010; Lopez Pita et al. 2004).

Optimal gradation of sub-ballast aggregate mixture can be selected by using constrained and unconstrained optimization models for the design of hot mix asphalt (HMA) mixture gradation based on the gradation of mineral constituent (Sivilevičius et al. 2011).

A theoretical model of unsaturated soil is presented by Monnet and Boutonnier (2012). It takes into account the following three main components of soil: air, water and soil particles. It uses the principle of effective stress on four different domains: unsaturated with air in continuous phase (Domain D1), unsaturated with air occluded in contact with the particles of soil (Domain D2), unsaturated with air bubbles (Domain D3) and saturated with air dissolved into water (Domain D4).

The dynamic response of a vehicle running on the track structure with irregularity profiles is predominantly due to the vibration of the bogie at lower frequency than fundamental frequencies of the track structure. The dynamic effects of high-speed load on ballasted track have been studied using a simplified 2D finite-element model, which neglects lateral effects and considers a discrete model for ballast and subgrade. Another model is a full 3D finite-element model with continuum elements for ballast and subgrade and infinite elements to consider the shape effects of aggregate particles on assembly behavior in the boundary (Nguyen et al. 2014).

The discrete-element method (DEM) provides more realistic results compared with those of continuum analysis for unbound construction materials such as railroad ballast (Huang, Tutumluer 2014; Nguyen et al. 2014).

Classical and numerical methods were discussed by Shoaei et al. (2012) and Guler (2014) with respect to the two-layered deformations and their behaviour under load. One of the methods is Artificial Neural Network (ANN) which is an advanced interpolation tool capable of predicting different soil characteristics.

The Bayesian model for rail track geometry degradation allows assessing the evolution of uncertainty associated with degradation parameters throughout the rail track life cycle. Prior probability distributions were fitted to track geometry degradation, showing that Log-Normal distribution is the most suitable distribution to model deterioration parameters (Andrade, Teixeira 2012).

Arasteh Khouy et al. (2014b) and Vale et al. (2012) reported that execution of tamping is highly dependent on the track condition data and there is no well-structured track degradation analysis that helps to plan maintenance in the long term. Evaluation of the standard deviation for the longitudinal level at which tamping is executed indicates that the execution of tamping is not optimally planned.

This research aims to systematize the required properties of railway sub-ballast layer and the factors determining them, to study the actual variation of gradation, density and water permeability of KG1 (in German: Korngemisch) mixture used for laying railway sub-ballast, to determine distribution normality and to estimate minimum representative sample size, when sampling is carried out in the locations where the mixture is produced and laid.

\section{Sub-ballast properties}

The aggregate sub-ballast (ASB) layer, situated under the track superstructure (under the crushed stone ballast 
layer), is a constituent part of subgrade intended for constructing a stable superstructure with a long-term service life. The sub-ballast (Fig. 1) is laid from KG1 mixture, which helps to protect subgrade (foundation) from the impact of moving load pressure on the track superstructure, also to protect frost-susceptible soils from frost impact, and water-susceptible soils from precipitation and capillary water (Apsauginio... 2013).

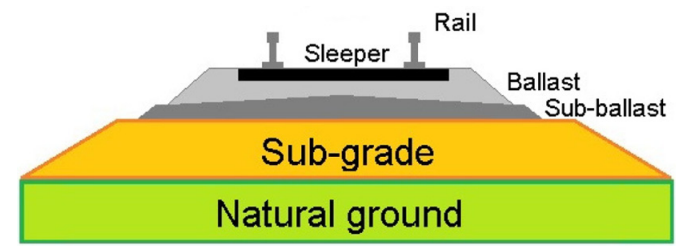

Fig. 1. Railway track structure

To serve the abovementioned functions, ASB material must meet the requirements given in Figure 2. The conformity of sub-ballast to its intended purpose and also its durability depend on 3 groups of factors: KG1 mixture properties (quality), sub-ballast laying technology from KG1 mixture, control and work acceptance system.

\section{Requirements to ASB mixture and its production}

\subsection{Uniformity coefficient of gradation curve and the rate of curvature}

Uniformity coefficient of aggregate mixture $C_{u}$ describes the sharpness of gradation curve within the interval from $d_{10}$ to $d_{60}$. The lower uniformity coefficient $C_{u}$, the more uniform and better sorted aggregate mixture is.

Uniformity coefficient of the sub-ballast mixture $\mathrm{KG} 1$ is defined by the following formula (1):

$$
C_{u}=\frac{d_{60}}{d_{10}},
$$

where $d_{10}, d_{60}$ - the grain diameter at $10 \%$ and $60 \%$ passing (respectively), $\mathrm{mm}$.

When $d_{10}=0.125 \mathrm{~mm}$ and $d_{60}=4 \mathrm{~mm}$, the uniformity coefficient $C_{u}=32$.

The rate of curvature $C_{c}$ describes the shape of gradation curve of KG1 mixture within the interval $d_{10}$ and $d_{60}$ and is calculated by the following formula (2):

$$
C_{c}=\frac{\left(d_{30}\right)^{2}}{d_{10} \cdot d_{60}},
$$

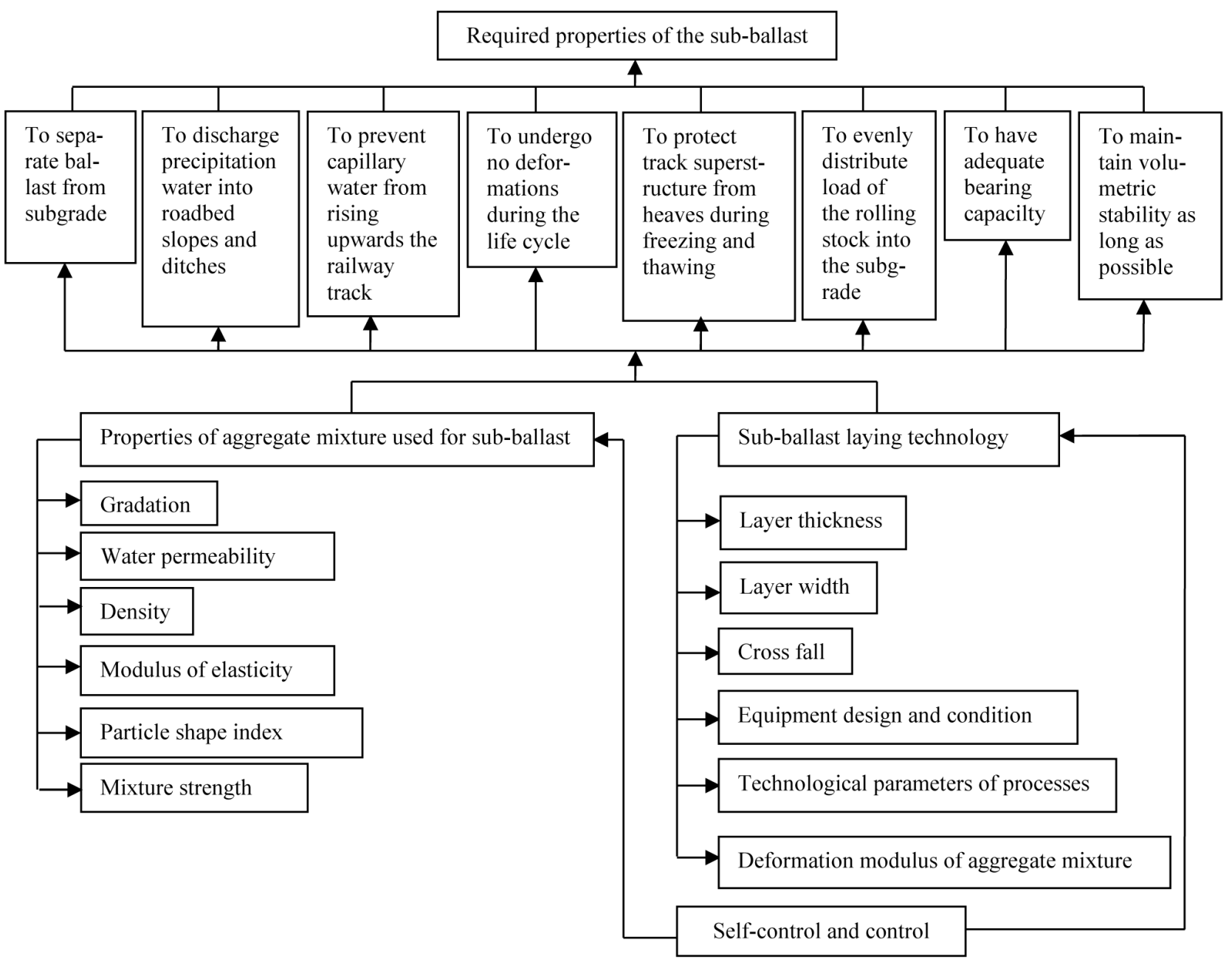

Fig. 2. Required properties of the sub-ballast and factors determining them 
where $d_{10}, d_{30}, d_{60}$ - the grain diameter at $10 \%, 30 \%$ and $60 \%$ passing (respectively), $\mathrm{mm}$.

Having taken from the curve of arithmetic means of KG1 mixture gradation the grain diameters corresponding to $10 \%, 30 \%$ and $60 \%$ passing through the sieves, it was obtained that $d_{10}=0.125 \mathrm{~mm}, d_{30}=0.5 \mathrm{~mm}$ and $d_{60}=4 \mathrm{~mm}, C_{c}=0.5$. Calculation results show that ASB mixture according to uniformity coefficient $C_{u}$ value is good curvature $(\mathrm{G})$ soil $(32 \geq 6)$, and according to the rate of curvature $C_{c}$ value $(0.5<1)$ it is various curvature $(\mathrm{P})$ soil (Table 1).

Table 1. Classification of soils by uniformity coefficient and rate of curvature (LST 1331:2015)

\begin{tabular}{lccc}
\hline \multicolumn{1}{c}{ Description } & Symbol & $\begin{array}{c}\text { Uniformity } \\
\text { coefficient } \\
C_{u}\end{array}$ & $\begin{array}{c}\text { Rate of } \\
\text { curvature } \\
C_{c}\end{array}$ \\
\hline Bad curvature soil & $\mathrm{B}$ & $<6$ & Any \\
\hline Good curvature soil & $\mathrm{G}$ & $\geq 6$ & $1<C_{c}<3$ \\
\hline Various curvature soil & $\mathrm{P}$ & $\leq 6$ & $<1$ or $>3$ \\
\hline
\end{tabular}

\subsection{Indicator of ASB mixture gradation variation}

In the course of segregation processes the inhomogeneity of ASB mixture increases. The variation of gradation is expressed in terms of standard deviations in percent passing all the sieves $s_{p}$. Their values depend on the arithmetic mean of percent passing the sieves $\bar{p}$ and on the homogeneity of the material. The variation of gradation of granular material or aggregate mixture was suggested (Mučinis et al. 2009) to be determined based on the max value of percent passing $s_{p \max }$. The correlation $s_{p}=f(\bar{p})$, obtained by the experimental research of gradation, makes it possible to estimate $s_{p \max }$ of granular material, taking no consideration of the mesh size of laboratory sieves. The standard deviation of percent passing varies depending on their arithmetic mean according to the regression model:

$$
s_{p}=\sqrt{a \cdot \bar{p}^{b} \cdot(100-\bar{p})^{c}},
$$

where $a, b, c$-respective unknown parameters of the model which determine the shape of the curve and its asymmetry; $s_{p}$ - the standard deviation of percent passing through any sieve, $\% ; \bar{p}$ - the arithmetic mean of percent passing through the given sieve, $\%$.

The model (3) shows that the highest $s_{p \max }$ is represented by the grains the content of which makes about $50 \%$ of the mixture mass.

\subsection{Water permeability of ASB mixture}

Water permeability $k$ of the sub-ballast mixture KG1 depends on the average size of voids. It is also affected by the size and shape of grains and the ratio of grains of different size. Water permeability of the mixture is determined according to the LST CEN ISO/TS 17892-11 (2005) methodology. When testing this property of KG1 mixture, the water permeability of the mixture of de-

stroyed structure is determined under constant pressure and certain hydraulic gradient. Water passes through the sample in a laminar flow. During the test the volume of water passing through a sample during certain time is measured.

Water permeability $(\mathrm{m} / \mathrm{s})$ is expressed as the velocity of water flow in aggregate mixture and is calculated by the formula:

$$
k=\left(\frac{a \cdot l}{A \cdot t}\right) \ln \frac{h_{1}}{h_{2}},
$$

where: $a$ - the cross-sectional area of the piezometric tube, $\mathrm{m}^{2} ; l-$ the sample's height during the test, $\mathrm{m}$; $A$ - the cross-sectional area of the sample, $\mathrm{m}^{2} ; t-$ the interval between measurements, $\mathrm{s} ; h_{1}$ the piezometric head at the start of the selected interval, $\mathrm{m} ; h_{2}$ the piezometric head at the end of the selected interval, $m$.

Water permeability is prescribed by the LST CEN ISO/TS 17892-11 (2005) and shall be $k \leq 1 \cdot 10^{-6} \mathrm{~m} / \mathrm{s}$. If slag is used, it shall be $k \leq 1 \cdot 10^{-5} \mathrm{~m} / \mathrm{s}$.

\section{Experimental research}

\subsection{Production technologies and transportation}

When screening the quarried gravel it is difficult to select such technological parameters which would allow to obtain aggregate mixture of wide range gradation (from 0 to $32 \mathrm{~mm}$ of particle size) suitable for laying the subballast layer. Due to the variation in raw material (quarried grave 1) gradation, the mixture may contain a lack or excess of fractions of certain size; therefore ASB mixture is produced from several (up to 4) fractions of different size and blended at the required mass ratio in a technological facility.

ASB mixture, used for laying railway sub-ballast, is produced in a special stationary continuous facility (Fig. 3). Aggregates of different gradation are loaded by the shovel to separate acceptance hoppers. Based on the selected optimal gradation of KG1 mixture, separate aggregate fractions are dosed in flows in different masses. The height of the unloading end of a transporter belt is fixed in such a way that the falling down KG1 mixture minimally segregates and partly in a gravitational way mixes in a newly formed stockpile. At the end of a trans-

a)

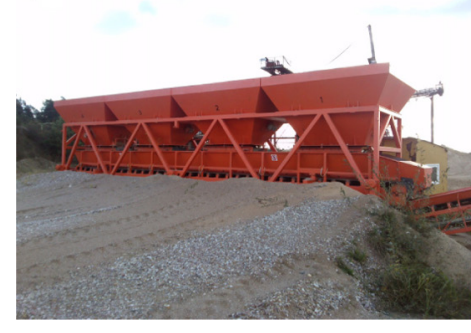

Fig. 3. ASB mixture production facility containing four different materials and fraction groups in dosing bunkers: a - loading ramp to the acceptance hoppers; $\mathrm{b}$ - ASB mixture production plant 
porter belt initial segregation processes occur. As a rule, course-grained aggregate fractions fall down to the bottom of a stockpile, and fine-grained fractions accumulate in the centre of a stockpile.

During the technological process (Fig. 4) the ASB mixture is continuously produced and stored in the 1'st cone-shape stockpile. The mixture is loaded from the stockpile to the trucks, transported to the construction site and unloaded on subgrade. The unloaded mixture is spread by a grader in a layer of required thickness and is then compacted.

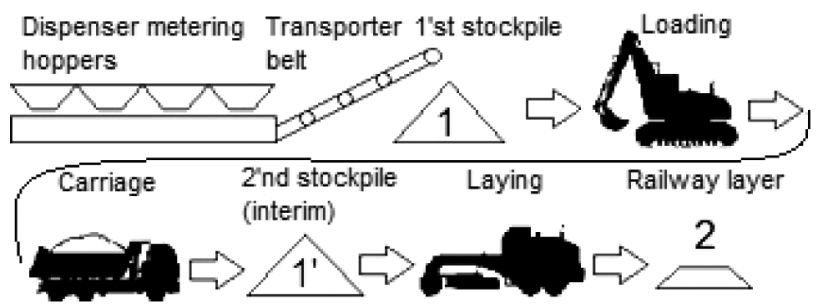

Fig. 4. The scheme of KG1 mixture transportation and use

In the course of all technological operations the mixture undergoes segregation. When loading or blending the grains of different size, the homogeneity of ASB mixture can worsen or get better.

\subsection{Sample size}

To determine the properties of ASB mixture, in 2014, its samples were taken from two different locations of the technological process: a stockpile and a railway layer (Fig. 4). Table 2 gives the number of samples for which three properties were determined. All individual samples were tested by standard laboratory methods. For each ASB mixture property the parameter of position (arithmetic mean) and variation (standard deviation) was determined. Histograms and theoretical curves of normal distribution were constructed. The data distribution conformity to normal (Gaussian) law was checked.

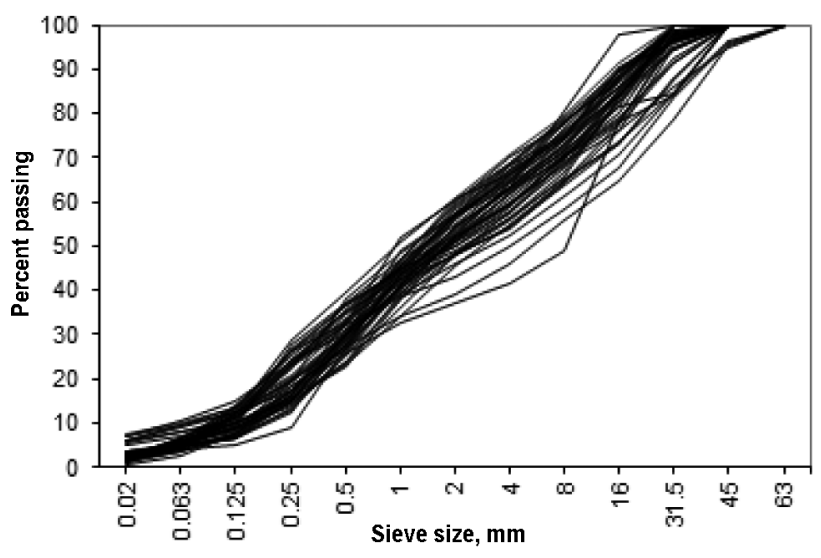

Fig. 5. Gradation of individual samples of railway sub-ballast layer

Table 2. Number of ASB samples taken from different locations of the technological process

\begin{tabular}{lccc}
\hline \multirow{2}{*}{$\begin{array}{c}\text { Sampling } \\
\text { location }\end{array}$} & \multicolumn{3}{c}{ Sample size for the indicator } \\
\cline { 2 - 4 } & $\begin{array}{c}\text { Gradation } \\
p_{i}, \%\end{array}$ & $\begin{array}{c}\text { Mixture } \\
\text { density } \\
\rho, \mathrm{Mg} / \mathrm{m}^{3}\end{array}$ & $\begin{array}{c}\text { Water } \\
\text { permeability, } \\
k, \mathrm{~m} / \mathrm{s}\end{array}$ \\
\hline Stockpile & 14 & 14 & 14 \\
\hline Railway layer & 35 & 35 & 35 \\
\hline Total & 49 & 49 & 49 \\
\hline
\end{tabular}

\subsection{Results of gradation variation in KG1 mixture}

Having determined gradation of all individual ASB mixture samples $(n=49)$, taken from different locations, the results of gradation variation were obtained (Fig. 5).

A rather wide field of variation in gradation curves of ASB mixture samples (Fig. 5) shows that the subballast layer material is inhomogeneous. Histograms of the distribution of percent passing through all laboratory sieves, theoretical curves of normal distribution and the estimated statistical parameters of position and variation (Fig. 6) differ.
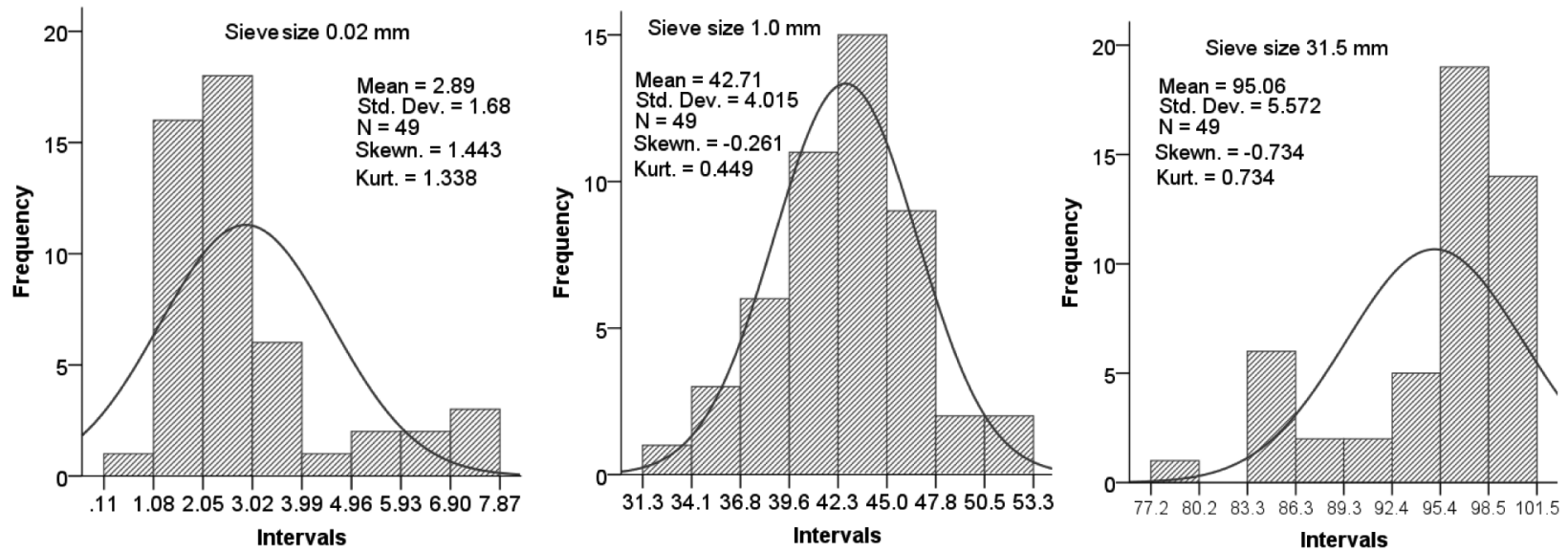

Fig. 6. Histograms of the ASB mixture percent passing, theoretical curves of normal distribution and statistical indicators 
Table 3. Gradation variation in ASB mixture

\begin{tabular}{lccccccccccccc}
\hline \multirow{2}{*}{ Statistical indicator } & \multicolumn{10}{c}{ Percent passing through the sieves (mm) } \\
\cline { 2 - 22 } & 0.02 & 0.063 & 0.125 & 0.25 & 0.5 & 1 & 2 & 4 & 8 & 16 & 31.5 & 45 \\
\hline Mean & 2.89 & 5.75 & 10.10 & 19.36 & 30.51 & 42.71 & 52.72 & 61.20 & 70.96 & 82.97 & 95.06 & 99.64 \\
Standard deviation & 1.68 & 1.70 & 2.39 & 4.66 & 4.11 & 4.02 & 5.25 & 6.12 & 6.36 & 6.54 & 5.57 & 1.25 \\
Coefficient of variation & 58.1 & 29.6 & 23.7 & 24.1 & 13.5 & 9.4 & 10.0 & 10.0 & 9.0 & 7.9 & 5.9 & 1.3 \\
\hline
\end{tabular}

Fine particles (from $0.02 \mathrm{~mm}$ to $0.063 \mathrm{~mm}$ ) have a positive (right-side) asymmetry, since most of them get into histogram intervals (classes) situated to the left of the arithmetic mean.

Based on the mathematical model (3), from means $\bar{p}$ and standard deviations $s_{p}$, given in Table 3, correlation regression equation $s_{p}=f(\bar{q})$ of these statistical indicators was obtained and its determination coefficient $R^{2}=0.909$ (Fig. 7) showing that the variation in $s_{p}$ is by about $91 \%$ determined by variation in $\bar{q}$ and only $9 \%$ of variation in $s_{q}$ depends on other parameters not considered in the model.

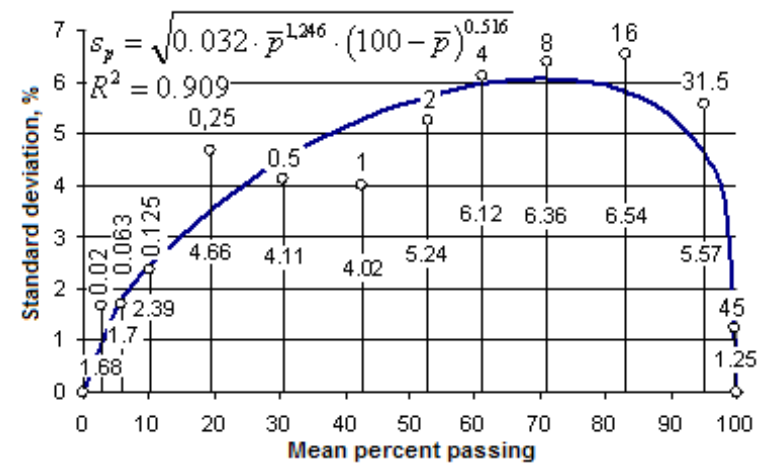

Fig. 7. Correlation between the parameters of ASB mixture gradation variation $\left(s_{p}\right)$ and position $(\bar{p})$ with equation of homogeneity

\subsection{Mixture density and water permeability}

Suitability of aggregate mixture for constructing a railway sub-ballast layer is demonstrated not only by its gradation but also by its density and water permeability. The sub-ballast layer is divided into the layer of low permeability (KG1) and that of increased permeability (KG2) (Apsauginio... 2013).

The mean density of 49 individual samples of ASB mixture is $2.112 \mathrm{Mg} / \mathrm{m}^{3}$ (2112 kg/m ${ }^{3}$ ) (Fig. 8); whereas the mean water permeability is $0.6407 \cdot 10^{-6} \mathrm{~m} / \mathrm{s}$. The data obtained showed that the density of ASB mixture is scattered within a narrow range (variation coefficient $v=3.9 \%)$; whereas, water permeability is scattered within a very wide range $(v=176.3 \%)$. The results of water permeability in ASB mixture contain the outliers (Fig. 9).

Having excluded three outliers, situated outside the limits $\pm 3 s_{k}$, statistical parameters were estimated and a new histogram was constructed (Fig. 10). They show that

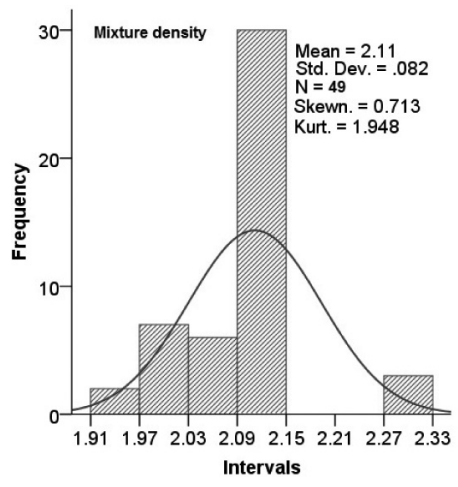

Fig. 8. Histograms of ASB mixture density theoretical curve of normal distribution and statistical indicators

the arithmetic mean of water permeability decreased almost twice (from 0.000000641 to 0.000000365 ); whereas standard deviation decreased by 3.4 times (from 0.00000113 to 0.000000331 ).

When estimating min size of a representative sample of ASB mixture with respect to water permeability, the data of Figure 10 was used (Table 6).

\subsection{Normal distribution of results}

ASB mixture, used for laying the railway sub-ballast, due to the variation in technological process parameters and raw-material properties, also due to its segregation in a stockpile, has certain inhomogeneity. Its inhomogeneity is indicated by the parameters of variation in its gradation and other properties (standard deviation, variance, variation coefficient). In order to compare stochastically distributed samples in terms of variation parameters, it is necessary to identify if they conform to the normal (Gaussian) law.

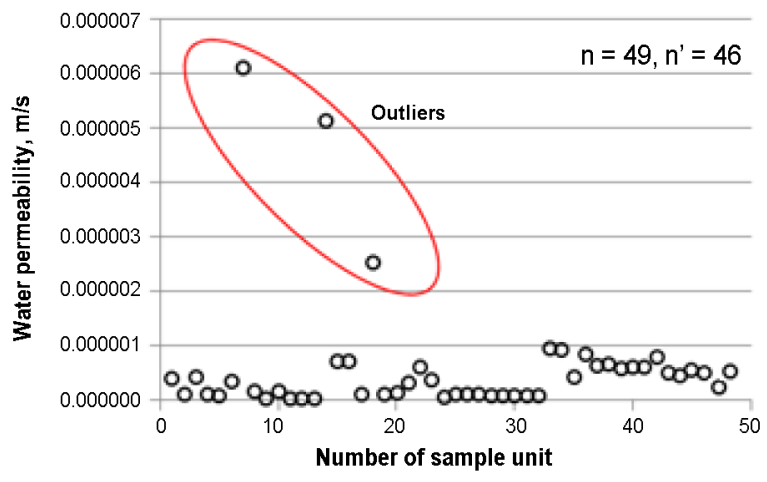

Fig. 9. A scatter diagram of ASB mixture of KG1 type water permeability with the outliers 


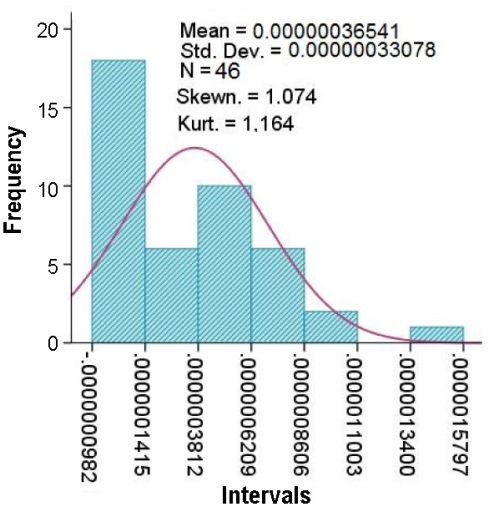

Fig. 10. Histogram of water permeability without outliers and statistical indicators

When testing random sample for normality, skewness (Skew) and kurtosis (Kurt) as well as the following methods: Kolmogorov-Smirnov (KS) (Conover 1999), Shapiro-Wilk (SW) (Miller 1986; Madansky 1988; Raza1i, Wah 2011; Shapiro, Wilk 1965), Pearson $\left(\chi^{2}\right)$ are used.

Table 4 gives the results of testing the conformity to normal distribution through the use of different methods.

The results of testing the conformity of empirical (experimental) data distribution to normal distribution (Table 4) show that according to five methods the most properties of KG1 mixture meet Gaussian distribution (Table 4, marked by “+”).

Considering the sample size $n=49$, shown in Table 3 , the values of standard deviation skewness $\left(s_{s k}\right)$ and kurtosis $\left(s_{k u}\right)$ were estimated by methodology
(Sivilevičius, Vansauskas 2013). The values of skewness $s_{s k}$ multiplied by 3 , which are 1.699 , respectively, is lower than $s_{k}$ values estimated from the measurement data given in Table 3, except a $45 \mathrm{~mm}$ sieve. The standard deviation values of kurtosis $s_{k u}$ multiplied by 5 are 3.340 and are lower than $\mathrm{Ku}$ values estimated from the measurement data given in Table 3, except a $45 \mathrm{~mm}$ sieve. With respect to Kolmogorov-Smirnov (KS), Shapiro-Wilk (SW), and Pearson $\left(\chi^{2}\right)$, this data reasonably leads to the conclusion that the materials are distributed according to the normal law.

\section{ASB mixture homogeneity change}

\subsection{Differences in the gradation of the produced and laid KG1 mixture}

During loading and transportation the arithmetic means of percent passing of sub-ballast mixture through the control sieves undergoes changes (Fig. 11). Due to mechanical factors the material gets finer. Comparing the KG1 mixture samples taken from a stockpile and from a railway layer, it is clear that the arithmetic means of stockpiled samples with the fractions from $2 \mathrm{~mm}$ to $31.5 \mathrm{~mm}$ were higher than those of the samples taken from a railway layer, and with fractions from $0.02 \mathrm{~mm}$ to $1 \mathrm{~mm}$, on the contrary, the arithmetic means of samples taken from the layer were higher.

Higher values of percent passing of fine fractions (up to $2 \mathrm{~mm}$ ), determined in the KG1 mixture samples taken from the railway sub-ballast layer show that in the technological process of loading and transportation the mixture has a tendency to become finer. However, the

Table 4. Conformity of data distribution to the reguirements of normal distribution

\begin{tabular}{|c|c|c|c|c|c|c|c|c|c|c|c|}
\hline \multirow{2}{*}{\multicolumn{2}{|c|}{ Parameter }} & \multicolumn{10}{|c|}{ Methods of normal distribution testing } \\
\hline & & $\mathrm{Sk}$ & Conclusion & $\mathrm{Ku}$ & Conclusion & $\mathrm{KS}$ & Conclusion & SW & Conclusion & $\chi^{2}$ & Conclusion \\
\hline \multirow{12}{*}{ 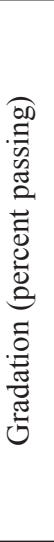 } & 0.02 & 1.443 & - & 1.338 & + & 0.000 & + & 0.000 & + & 60.5 & + \\
\hline & 0.063 & 1.296 & - & 1.620 & + & 0.000 & + & 0.000 & + & 63.4 & + \\
\hline & 0.125 & 0.003 & + & -1.012 & + & 0.200 & + & 0.246 & + & 15.5 & + \\
\hline & 0.25 & 0.196 & + & -0.852 & + & 0.057 & + & 0.138 & + & 25.6 & + \\
\hline & 0.5 & 0.215 & + & -0.486 & + & 0.200 & - & 0.729 & + & 20.4 & + \\
\hline & 1 & -0.261 & + & 0.449 & + & 0.200 & - & 0.703 & + & 37.7 & + \\
\hline & 2 & -0.781 & + & 0.981 & + & 0.200 & - & 0.046 & + & 61.5 & + \\
\hline & 4 & -0.985 & + & 1.256 & + & 0.091 & + & 0.019 & + & 38.1 & + \\
\hline & 8 & -1.177 & - & 2.108 & + & 0.069 & + & 0.005 & + & 42.9 & + \\
\hline & 16 & -0.714 & + & 0.656 & + & 0.012 & + & 0.057 & + & 48.5 & + \\
\hline & 31.5 & -0.734 & + & 0.734 & + & 0.000 & + & 0.000 & + & 37.7 & + \\
\hline & 45 & -3.269 & - & 9.323 & - & 0.000 & + & 0.000 & + & 282.6 & - \\
\hline \multicolumn{2}{|c|}{ Density } & 0.713 & + & 1.948 & + & 0.000 & + & 0.000 & + & 140.6 & - \\
\hline \multicolumn{2}{|c|}{$\begin{array}{l}\text { Water } \\
\text { permeability }\end{array}$} & 3.851 & - & 15.677 & - & 0.000 & + & 0.000 & + & 126.8 & - \\
\hline
\end{tabular}

Note: The critical values of normal distribution testing by different methods: triple standard deviation of skewness: $3 s_{s k}=1.02$; five-times standard deviation of kurtosis: $5 s_{k u}=3.340$; Kolmogorov-Smirnov: $d_{0.05}=0.194$; Shapiro-Wilk: $w_{c}=0.947$; Pearson: $\chi_{0.05}^{2}=65.2$. 


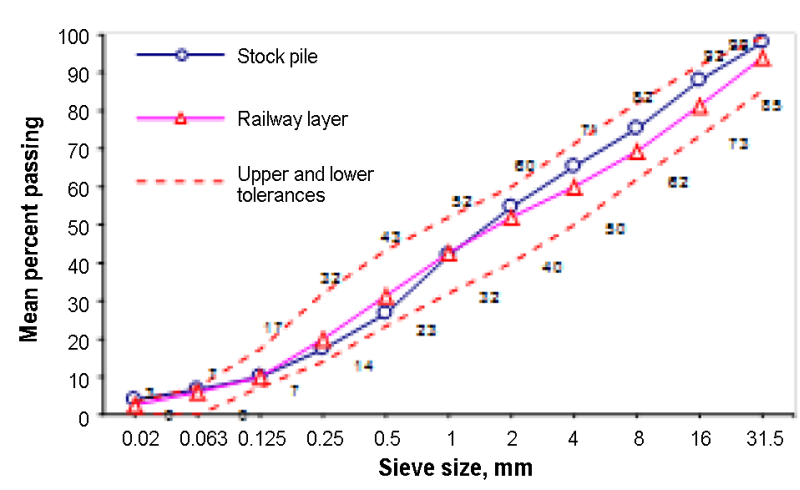

Fig. 11. Conformity of the average gradation of ASB mixture type KG1 samples, taken from different locations, to the technological requirements

mean gradation of the mixture after it became finer met the technical requirements of DIN - Taschenbuch 113 (1998a, 1998b), since its curve was ranging within the upper $p_{u}$ and lower $p_{L}$ limits (Fig. 11).

\subsection{Variation parameters and their conformity to tolerances}

Even though the mean gradation meets the set technical requirements, due to a large variation in the gradation of individual samples, part of KG1 mixture fails to meet those requirements (Fig. 13) and can be treated as spoilage. There are no statistical tolerances set for KG1 mixture gradiation that would show max deviation in the gradation of an individual sample from the job-mix formula.
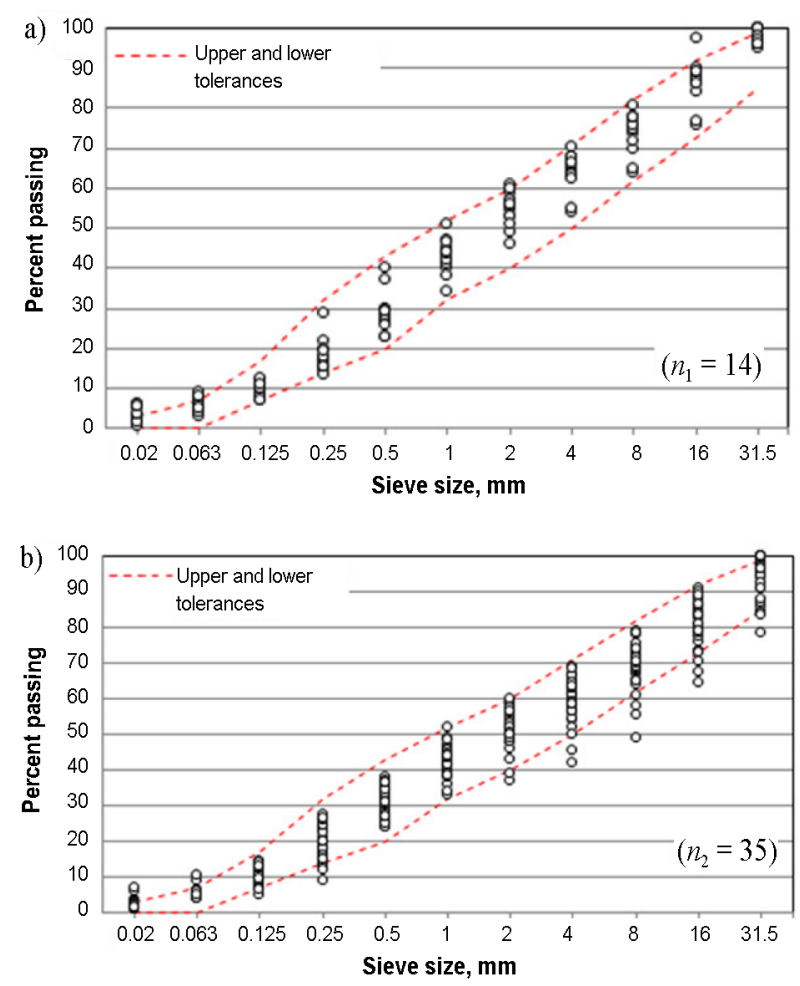

Fig. 12. Diagrams of gradation for samples taken from $-a$ the stockpile, and $b$ - the railway layer.
The width of a variation field of individual samples, taken from the stockpile (Fig. 12a) was smaller than that of samples taken from the railway layer (Fig. 12b). Increase in the gradation variation of KG1 mixture, laid in railway layer, shows that due to segregation processes the mixture became not only finer but also less homogenic.

\subsection{Homogeneity of the mixture produced in ASB and in the railway layer}

With the help of the theoretical mathematical model (Eqn (3)) the regression equations of KG1 mixture gradation were obtained from experimental data for samples taken from the stockpile and from the sub-ballast layer (Fig. 13). The highest values of standard deviations $s_{p \max }$ were obtained for percent passing those sieves the means $\bar{p}$ of which make up 50-70\%.

The values of determination coefficient $R^{2}$ approximately to 1 show that the variation in standard deviation of percent passing the sieves $s_{p}$ by more than $90 \%$ is determined by the variation in the arithmetic mean $\bar{p}$. Therefore, it could be stated that the obtained regression equations (Fig. 13) are reliable. The ordinates, estimated based on these equations, show a strong correlation between gradation variance and position characteristics of KG1 mixture and can be used for determining gradation variation of samples taken from different locations.
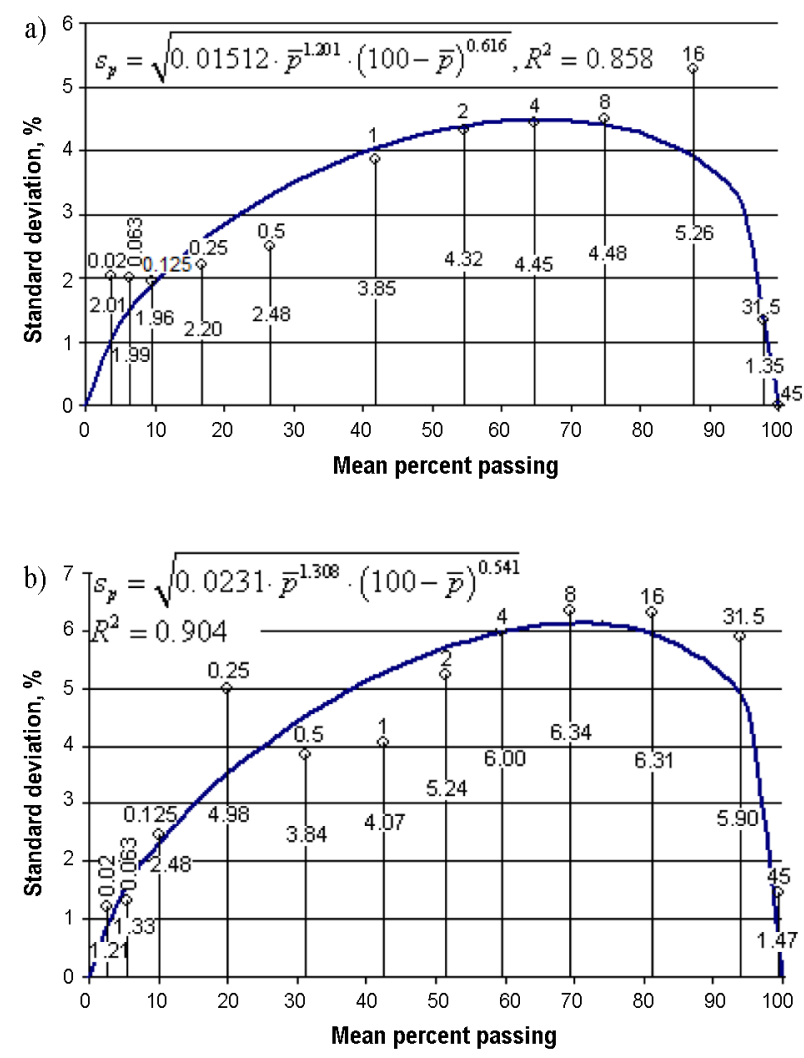

Fig. 13. Correlation between the statistical parameters of ASB mixture gradation: $\mathrm{a}$ - in a stockpile; $\mathrm{b}$ - in a railway subballast layer 


\subsection{Research in the uniformity of variances}

Bartlett criterion is relevant only in case the monitored variables have normal distribution (Table 4).

To check if there is any statistical difference in the variances of normally distributed properties of KG1 mixture samples taken from different locations (in the stockpile and in the railway layer), the Bartlett's criterion was used:

$$
B=\frac{E}{C}=\frac{2.303\left[k \cdot \log _{10} \bar{s}^{2}-\sum_{i=1}^{l} k_{i} \log _{10} s_{i}^{2}\right]}{1+\frac{1}{3(1-1)}\left[\sum_{i=1}^{l} \frac{1}{k_{i}}-\frac{1}{k}\right]},
$$

where $l$ - the number KG1 mixture samples analyzed, i.e. the number of sampling locations (in this research $l=2$ ); $k_{i}=n_{i}-1$ the number of freedom degrees; $n_{i}-$ the number of analyzed samples of the $i$-th sampling location (in this research $\left.n_{1}=14, n_{2}=35\right) ; k=\sum_{i=1}^{l} k_{i} ; s_{i}^{2}-$ the shift variance of percent passing through the sieves of the $i$-th sampling location; $s_{i}$ - its standard deviation; $\bar{s}^{2}-$ the weighted mean of variances in all samples taken from all locations (Eqn (6)).

The above criterion is considered suitable for checking the uniformity of variances since the size of samples is different: $n_{1}=14$ and $n_{2}=35$.

KG1 mixture gradation (percent passing) $s_{p \max }=4.51 \%$ and $s_{p \max }=6.14 \%$, water permeability $s_{p \max }=3.74 \cdot 10^{-7} \mathrm{~m} / \mathrm{s}$ and $s_{p \max }=2.87 \cdot 10^{-7} \mathrm{~m} / \mathrm{s}$, density $s_{p \max }=0.092 \mathrm{~kg} / \mathrm{m}^{3}$ and $s_{p \max }=0.081 \mathrm{~kg} / \mathrm{m}^{3}$.

$$
\bar{s}^{2}=\frac{\sum_{i=1}^{l} k_{i} s_{i}^{2}}{k}
$$

the critical $\chi_{v, \infty}^{2}(\alpha, \infty)$ value $\chi_{v, \infty}^{2}(0.05, \infty)=3.84$.

Comparison of the variances in aggregate percent passing and mixture density of two locations of technological process showed that, given the assumed level of significance $\alpha=0.05$, they do not differ statistically, i.e. they are uniform (Table 5).

\section{Minimum representative sample size}

To determine gradation or other physical or mechanical quality indicator of inhomogeneous aggregate mixture, random subsamples are taken, a minimum number of which is calculated by the following formula:

$$
n=\frac{t^{2} \cdot \sigma^{2}}{\Delta^{2}}
$$

where $n$ - the number of samples, $t$ - the desired degree of assurance, or probability of success in obtaining a correct answer measured in standard deviation units from
Table 5. The results of checking uniformity of variances in

\begin{tabular}{|c|c|c|c|c|}
\hline Property & Location & $\begin{array}{l}\text { Standard } \\
\text { deviation }\end{array}$ & $\begin{array}{c}\text { Statistic } \\
\text { B }\end{array}$ & Conclusion \\
\hline \multirow{2}{*}{ Gradation } & $\mathrm{SP}$ & 4.51 & \multirow{2}{*}{3.07} & \multirow{2}{*}{ Uniform } \\
\hline & $\mathrm{RL}$ & 6.14 & & \\
\hline \multirow{2}{*}{$\begin{array}{l}\text { Mixture } \\
\text { density }\end{array}$} & SP & 0.092 & \multirow{2}{*}{0.27} & \multirow{2}{*}{ Uniform } \\
\hline & $\mathrm{RL}$ & 0.081 & & \\
\hline \multirow{2}{*}{$\begin{array}{l}\text { Water } \\
\text { permeability }\end{array}$} & SP & $3.74 \cdot 10^{-7}$ & \multirow{2}{*}{0.72} & \multirow{2}{*}{ Uniform } \\
\hline & RL & $2.87 \cdot 10^{-7}$ & & \\
\hline
\end{tabular}
KG1 mixture samples taken from different locations based on Bartlett's criterion

Note: $\mathrm{SP}$ - Stockpile; RL - Railway layer; $\chi_{v, \infty}^{2}=3.84$.

the centre of the $\mathrm{t}$ distribution curve; $\sigma$ - the overall standard deviation of measurements; $\Delta-$ the permissible relative error between the calculated mean measurements and the actual mean.

When significance level of the two-sided test of Student's distribution is assumed as 95\% (the number of freedom degrees is assumed as $\infty$ ), then $\alpha=0.05$, and $t=1.96$.

The permissible relative error is calculated by the formula:

$$
\Delta=\frac{\delta \cdot \bar{X}}{100}
$$

where $\delta$ - a permissible relative error (can be equal to $5 \%, 10 \%, 15 \%$ or $20 \%) ; \bar{X}$ - the arithmetic mean of the quality indicator.

Material gradation can be expressed in terms of partial percent of aggregate retained in the sieves, cumulative percent of aggregate retained in the sieves and percent of aggregate passing through the sieves. Therefore, the arithmetic mean, calculated for each sieve by each of those three methods, differs. Usually, gradation of aggregate or aggregate mixture is expressed in percent passing through the sieves. Therefore, gradation variation in KG1 mixture was determined based on the max value of standard deviation $s_{p \max }$ corresponding to the arithmetic mean of percent passing $\bar{p}$ which is close to $50-70 \%$ (Fig. 13).

The permissible relative error $(\delta)$ is assumed as $5 \%, 10 \%, 15 \%$ and $20 \%$. Table 6 gives the results of calculations.

Maximum standard deviations $s_{p \max }$ were obtained in KG1 mixture samples taken from the stockpile (4.51\%) when the mean percent passing was $70 \%$, and from the railway layer $(6.14 \%)$ when the mean percent passing was 70\% (Table 6).

When permissible relative error $\delta=10 \%$, the obtained minimum sample size from the stockpile $n=4$ and from the layer $n=6$.

Min representative sample size for determining the density of KG1 mixture when $\delta=5 \%$ shall be $n=4$, and when $\delta=(10-20) \%, n=1$ (Table 6). 
Table 6. Minimum number of samples for determining the KG1 mixture properties

\begin{tabular}{|c|c|c|c|c|c|c|c|c|c|c|c|c|}
\hline \multirow{3}{*}{ Statistical indicator } & \multicolumn{12}{|c|}{ The permissible relative error $\delta(\%)$ when the sampling location is } \\
\hline & \multicolumn{4}{|c|}{ All locations } & \multicolumn{4}{|c|}{ Stockpile } & \multicolumn{4}{|c|}{ Railway layer } \\
\hline & 5 & 10 & 15 & 20 & 5 & 10 & 15 & 20 & 5 & 10 & 15 & 20 \\
\hline & \multicolumn{12}{|c|}{ Gradation } \\
\hline Mean, $\%$ & \multicolumn{4}{|c|}{70} & \multicolumn{4}{|c|}{65} & \multicolumn{4}{|c|}{70} \\
\hline Max standard deviation, $\%$ & \multicolumn{4}{|c|}{6.07} & \multicolumn{4}{|c|}{4.51} & \multicolumn{4}{|c|}{6.14} \\
\hline Coefficient of variation, $\%$ & \multicolumn{4}{|c|}{8.7} & \multicolumn{4}{|c|}{6.9} & \multicolumn{4}{|c|}{8.8} \\
\hline \multirow[t]{2}{*}{ Sample size $n$} & 23 & 6 & 3 & 2 & 13 & 4 & 2 & 1 & 24 & 6 & 3 & 2 \\
\hline & \multicolumn{12}{|c|}{ Mixture density } \\
\hline Mean, $\mathrm{kg} / \mathrm{m}^{3}$ & \multicolumn{4}{|c|}{2.111} & \multicolumn{4}{|c|}{2.102} & \multicolumn{4}{|c|}{2.115} \\
\hline Max standard deviation, $\mathrm{kg} / \mathrm{m}^{3}$ & \multicolumn{4}{|c|}{0.0817} & \multicolumn{4}{|c|}{0.092} & \multicolumn{4}{|c|}{0.081} \\
\hline Coefficient of variation, $\%$ & \multicolumn{4}{|c|}{3.9} & \multicolumn{4}{|c|}{4.4} & \multicolumn{4}{|c|}{3.8} \\
\hline \multirow[t]{2}{*}{ Sample size $n$} & 3 & 1 & 1 & 1 & 4 & 1 & 1 & 1 & 3 & 1 & 1 & 1 \\
\hline & \multicolumn{12}{|c|}{ Water permeability } \\
\hline Mean, $\mathrm{m} / \mathrm{s}$ & \multicolumn{4}{|c|}{$3.65 \cdot 10^{-7}$} & \multicolumn{4}{|c|}{$2.55 \cdot 10^{-7}$} & \multicolumn{4}{|c|}{$4.13 \cdot 10^{-7}$} \\
\hline Max standard deviation, $\mathrm{m} / \mathrm{s}$ & \multicolumn{4}{|c|}{$3.31 \cdot 10^{-7}$} & \multicolumn{4}{|c|}{$3.74 \cdot 10^{-7}$} & \multicolumn{4}{|c|}{$2.87 \cdot 10^{-7}$} \\
\hline Coefficient of variation, $\%$ & & & & & & & & & & & & \\
\hline Sample size $n$ & 1265 & 317 & 141 & 80 & 3307 & 827 & 368 & 207 & 743 & 186 & 83 & 47 \\
\hline
\end{tabular}

Water permeability of KG1 mixture is distinguished by the largest variation from all its properties: its variation coefficient ranged from $147 \%$ (in samples from the stockpile) to $70 \%$ (in samples from the railway layer). Therefore, to determine this property, the largest sample size $n$ is necessary (Table 6).

\section{Conclusions}

1. In order to protect subgrade soil, the railway subballast layer is laid from $0 / 32 \mathrm{~mm}$ KG1 mixture of low permeability or from the frost resistant mixture KG2 of high permeability as well as from asphalt mixture. Aggregate mixture is produced according to the predetermined mass ratio of gravel and sand fractions of different coarseness, dosed in flows in a special technological facility. Due to the inhomogeneity of the mixture fractions (the number of fractions can reach 4), their dosing assumptions, incomplete blending when falling down from the transporter belt, and segregation processes in a cone-shape stockpile, the gradation of KG1 mixture differs from the job-mix formula, does not meet its technical requirements and contains certain variation. In order to increase the homogeneity of KG1 mixture, forced mixing machine should be added to the production process, which will cause inevitable segregation processes and therefore, will increase the homogeneity of the layer. The actual variation was determined by taking random samples of KG1 mixture of sufficiently large representative sizes.

2. In Lithuania, the gradation of the sub-ballast mixture KG1 was designed around 2012 in accordance with the requirements of German standard DIN - Taschenbuch 113 (1998a, 1998b); however, its evaluation is unknown.
It was also not known how this ASB mixture varies from in-plant to in-situ and if those changes are essential. To determine gradation variation, it is suggested to use max standard deviation of the particle percent passing through the sieves the content of which usually makes up $50-70 \%$ of the aggregate mass. The max standard deviation value allows to compare the aggregates and the mixtures of different coarseness and homogeneity. This original method enables to determine the size of gradation variation in any aggregate or granular mixture in one number (in max standard deviation).

3. The percent passing through the sieves, density and water permeability of KG1 mixture, used for laying the sub-ballast layer, based on 5 methods is normally distributed and this allows to employ conventional models of mathematical statistics when testing variation in these quality indicators. The outliers were detected only in water permeability testing sample. The true reason of the outliers was not successfully determined. One of main reasons is that water leaked through air voids in the laboratory sample.

4. The ready-for-use KG1 mixture in its technological process of loading, transportation, laying and compaction has a tendency to become finer and its gradation variation increases. Max standard deviation of percent passing through the sieves of the KG1 mixture sample taken from the stockpile was $4.5 \%$, and of the sample taken from the sub-ballast layer increased to $6.1 \%$ and was statistically different with the probability of 0.10 . The standard deviations of density and water permeability of both KG1 mixture samples were statistically uniform. The estimated min size of representative samples shows that more subsamples shall be taken from the subballast layer than from the stockpile. 


\section{References}

Andrade, A. R.; Teixeira, P. F. 2012. A Bayseian model to assess rail track geometry degradation through its life-cycle, Research in Transport Economics 36: 1-8. http://dx.doi.org/10.1016/j.retrec.2012.03.011

Apsauginio sankasos sluoksnio irengimo instrukcija. (275/K) (patvirtinta $A B$,Lietuvos geležinkeliai” genrealinio direktoriaus 2013 rugsèjo $6 \mathrm{~d}$. isakymu Nr. [-827). UAB „Geležinkeliu projektavimas“, Vilnius, 2013. 110 p. (in Lithuanian).

Arasteh Khouy, I.; Larsson-Kraik, P.; Nissen, A.; Juntti, U.; Schunnesson, H. 2014a. Optimisation of track geometry inspection interval, Proceedings of the Institution of $\mathrm{Me}$ chanical Engineers. Part F: Journal of Rail and Rapid Transit 228(5): 546-556. http://dx.doi.org/10.1177/0954409713484711

Arasteh Khouy, I.; Schunnesson, H.; Juntti, U.; Nissen, A.; Larsson-Kraik, P. 2014b. Evaluation of track geometry maintenance for a heavy haul railroad in Sweden: a case study, Proceedings of the Institution of Mechanical Engineers. Part F: Journal of Rail and Rapid Transit 228(5): 496-503. http://dx.doi.org/10.1177/0954409713482239

Bai, L.; Liu, R.; Sun, Q.; Wang, F.; Xu, P. 2015. Markov based model for the prediction of railway track irregularities, Proceedings of the Institution of Mechanical Engineers. Part F: Journal of Rail and Rapid Transit 229(2): $150-159$.

Bing, A. J.; Gross, A. 1983. Development of railway track degradation models, Transportation Research Record 939: 27-31.

Conover, W. J. 1999. Practical nonparametric statistics. $3^{\text {rd }}$ ed. New York: John Wiley\&Sons, Inc.

DIN-Taschenbuch 113, Erkundung des Baugrunds. 1998a. Bestimmung der Korngroessenverteilung DIN 18 123-1, DIN e.V., Wiesbaden, 273-284.

DIN-Taschenbuch 113, Erkundung des Baugrunds. 1998b. Bestimmung des Wasserdurchlaessigkeitsbeiwerts-teil 1: Laborversuch. DIN 18 130-1, DIN e.V., 336-355.

Esmaeili, M.; Rezaei, N. 2016. In situ impact testing of a lightrail ballasted track with tyre-derived aggregate sub-ballast layer, International Journal of Pavement Engineering 17(2): 176-188. http://dx.doi.org/10.1080/10298436.2015.1007226

European Asphalt Pavement Association. 2003. Asphalt ir railway tracks. Report. European Asphalt Pavement Associations, Brussels.

Fernandes, G.; Palmeira, E. M.; Gomes, R. C. 2008. Performance of geosynthetic-reinforced alternative subballast material in a railway track, Geosynthetics International 15(5): 311-321. http://dx.doi.org/10.1680/gein.2008.15.5.311

Gallego, I.; Munoz, J.; Sánchez-Cambronero, S.; Rivas, A. 2013. Recommendations for numerical rail substructure modeling considering nonlinear elastic behavior, Journal of Transportation Engineering 139(8): 848-858.

http://dx.doi.org/10.1061/(ASCE)TE.1943-5436.0000560

Guler, H. 2014. Prediction of railway track geometry deterioration using artificial neural networks: a case study for Turkish state railways, Structure and Infrastructure Engineering 10(5): 614-626. http://dx.doi.org/10.1080/15732479.2012.757791

Huang, H.; Tutumluer, E. 2014. Image-aided element shape generation method in discrete-element modeling for railroad ballast, Journal of Materials in Civil Engineering 26(3): 527-535.

http://dx.doi.org/10.1061/(ASCE)MT.1943-5533.0000839
Indraratna, B.; Nimbalkar, S. 2013. Stress-strain degradation response of railway ballast stabilized with geosynthetics, Journal of Geotechnical and Geoenvironmental Engineering 139(5): 684-700.

http://dx.doi.org/10.1061/(ASCE)GT.1943-5606.0000758

LST 1331:2015. Soils for use in road construction - classification. Lietuvos standartizacijos departamentas, 2015.

LST CEN ISO/TS 17892-11 Geotechnical investigation and testing - Laboratory testing of soil - Part 11: Determination of permeability by constant and falling head. European Commitee for Standartization, Brussels, 2005.

Lopez Pita, A.; Teixeira, P.F.; Robuste, F. 2004. High speed track deterioration: the role of the vertical stiffness of the track, Proceedings of the Institution of Mechanical Engineers. Part F: Journal of Rail and Rapid Transit 218(1): 3140. http://dx.doi.org/10.1243/095440904322804411

Madansky, A. 1988. Prescription for working statisticians. New York: Springer-Verlag. http://dx.doi.org/10.1007/978-1-4612-3794-5

Maskeliūnaite, L.; Sivilevičius, H. 2014. The model for evaluating the criteria describing the quality of the trip by international train, Technological and Economic Development of Economy 20(3): 484-506. http://dx.doi.org/10.3846/20294913.2014.949333

Miller, R. G., Jr. 1986. Beyond ANOVA, basics of applied Statistics. New York: John Wiley \& Sons.

Mishra, D.; Qian, Y.; Kazmee, H.; Tutumluer, E. 2014. Investigation of geogrid-reinforced railroad ballast behavior using large-scale triaxial testing and discrete element modeling, Transportation Research Record 2462: 98-108. http://dx.doi.org/10.3141/2462-12

Monnet, J.; Boutonnier, L. 2012. Calibration of an unsaturated air-water-soil model, Archives of Civil and Mechanical Engineering 12(4): 493-499. http://dx.doi.org/10.1016/j.acme.2012.07.001

Mučinis, D.; Sivilevičius, H.; Oginskas, R. 2009. Factors determining the inhomogeneity of reclaimed asphalt pavement and estimation of its components content variation parameters, Baltic Journal of Road and Bridge Engineering 4(2): 69-79. http://dx.doi.org/10.3846/1822-427X.2009.4.69-79

Nguyen, K.; Goicilea, J. M.; Galbadon, F. 2014. Comparsion of dynamic effects of high-speed traffic load on ballasted track using a simplified two dimensional and full threedimensional model, Journal of Rail and Rapid Transit 228(2): 128-142.

http://dx.doi.org/10.1177/0954409712465710

Podvezko, V.; Sivilevičius, H. 2013. The use of AHP and rank correlation methods for determining the significance of the interaction between the elements of a transport system having a strong influence on traffic safety, Transport 28(4): 389-403. http://dx.doi.org/10.3846/16484142.2013.866980

Razali, N. M.; Wah, Y. B. 2011. Power comparsions of Shapiros-Wilk, Kolmogorov-Smirnov, Lilliefors and AndersonDarling tests, Journal of Statistical Modeling and Analytics 2(1): 21-33.

Salour, F.; Erlingsson, S. 2015. Resilient modulus modeling of unsaturated subgrade soils: laboratory investigation of silty sand subgrade, Road Materials and Pavement Design 16(3): $553-568$. http://dx.doi.org/10.1080/14680629.2015.1021107

Selig, E. T.; Waters, J. M. 1994. Track geotechnology and substructure management. London: Thomas Telford Services Ltd. http://dx.doi.org/10.1680/tgasm.20139

Shahu, J. T.; Kameswara Rao, N. S. V.; Yudhbir. 1999. Parametric study of resilient response of tracks with a sub-ballast layer, Canadian Geotechnical Journal 36(6): 1137-1150. http://dx.doi.org/10.1139/t99-054 
Shapiro, S. S.; Wilk, M. B. 1965. An analysis of variance test for normality (complete samples), Biometrica 52(3/4): 591-611. http://dx.doi.org/10.2307/2333709

Shoaei, D. M.; Alkarni, A.; Noorzaei, J.; Jaafar, M. S.; Huat, B. K. 2012. Review of available approaches for ultimate bearing capacity of two-layered soils, Journal of Civil Engineering and Management 18(4): 469-482. http://dx.doi.org/10.3846/13923730.2012.699930

Sivilevičius, H.; Maskeliūnaitè, L. 2014. The numerical example for the evaluating the criteria describing the quality of the trip by international train, E\&M Economie a Management 17(2): 73-86.

http//dx.doi.org.10.15240/tul/001/2014-2-006

Sivilevičius, H.; Podvezko, V.; Vakrinienè, S. 2011. The use of constrained and unconstrained optimization models in gradation design of hot mix asphalt mixture, Construction and Building Materials 25(1): 115-122. http://dx.doi.org/10.1016/j.conbuildmat.2010.06.050

Sivilevičius, H.; Vansauskas, V. 2013. Research and evaluation of ruts in the asphalt pavement on Lithuanian highways, Journal of Civil Engineering and Management 19(5): 609-621.

http://dx.doi.org/10.3846/13923730.2013.817481
Soliman, H.; Shalaby, A. 2014. Characterising the elastic behaviour of fine-grained subgrade soils under traffic loading, International Journal of Pavement Engineering 15(8): 698-707. http://dx.doi.org/10.1080/10298436.2013.857773

Teixeira, P. F.; Ferreira, P. A.; López Pita, A.; Casas, C.; Bachiller, A. 2009. The use of bituminous subballast on future high-speed lines in Spain: structural design and economical impact, International Journal of Railway (2)1: 1-7. http://dx.doi.org/10.1016/j.sbspro.2012.09.888

Teixeira, P. F.; Lopez Pita, A.; Ferreira, P. A. 2010. New possibilities to reduce track costs on highspeed lines using a bituminous sub-ballast layer, International Journal of Pavement Engineering 11(4): 301-307. http://dx.doi.org/10.1080/10298431003749733

Vale, C.; Ribeiro, I. M.; Calçada, R. 2012. Integer programming to optimize tamping in railway tracks as preventive maintenance, Journal of Transportation Engineering 138(1): 123-131. http://dx.doi.org/10.1061/(ASCE)TE.1943-5436.0000296

Xu, P.; Sun, Q.; Liu, R.; Wang, F. 2011. A short-range prediction model for track quality index, Journal of Rail and Rapid Transit 225(3): 277-285. http://dx.doi.org/10.1177/2041301710392477

Deividas NAVIKAS. PhD student at the Department of Transport Technological Equipment of Vilnius Gediminas Technical University. He received his Master's degree in 2012 at Vilnius Gediminas Technical University. Research intrests: railway infrastructure elements, it's modelling and evaluation.

Henrikas SIVILEVIČIUS. Professor Dr Habil at Vilnius Gediminas Technical University. Education: Road construction engineering, VISI (VGTU), 1972, Candidate of technical sciences Moskow (MADI), 1984; Associate professor, VGTU, 1990; Doctor of technical sciences, VGTU, 1993; Doctor habilitaties, VGTU, 2003; Professor, VGTU, 2005. Publications: more than 200 scientific papers. Research intrests: flexible pavement life cycle, hot mix asphalt mixture production technology, application of statistical and quality control methods, recycling asphalt pavement technologies and design, decision-making and expert systems theory and applications, improvement railway passengers trip and infrastructure quality.

Matas BULEVIČIUS. Defend doctoral dissertation in 2014 at Vilnius Gediminas Technical University. He received his master degree in 2005 at Vilnius Gediminas Technical University. He is also the author and co-author of 3 publications as well as 8 research and technical reports. Currently is a director of JSC "Granitine skalda". He is a chairman of technical committee of road building materials and member of technical committee of geotechnical engineering of Lithuanian standards board. His research interests include mechanical-physical properties of aggregates, used for producing asphalt mixtures, bituminous binders, road pavement constructions. 